\title{
Susac syndrome
}

\section{Síndrome de Susac}

Fernando Freua ${ }^{1}$, Leandro Tavares Lucato², Flávio Villela ${ }^{3}$, Getúlio Daré Rabello ${ }^{4,5}$

Susac syndrome is a rare autoimmune endotheliopathy caused by a microangiopathic occlusive arteriolar disease ${ }^{1}$ characterized by the triad of encephalopathy, visual loss and sensorineural hearing loss 2 .

A 41-year-old man presented with migraine-like headache, transient visual loss and tinnitus. Brain MRI showed small scattered FLAIR-hyperintense lesions involving the corpus callosum, centrum semiovale and periventricular white matter bilaterally (Figures 1 and 2). Some of them presented restricted diffusion (Figure 3). CSF analysis revealed 6.0 cells $/ \mathrm{mm}^{3}$, a lymphomononuclear pattern, and elevated protein levels with an increase in gamma fraction (18.35\%). Angiofluorescein study showed retinian vasculitis (Figure 4). He was treated with immunoglobulin and methylprednisolone pulse ${ }^{3}$, presenting good results.

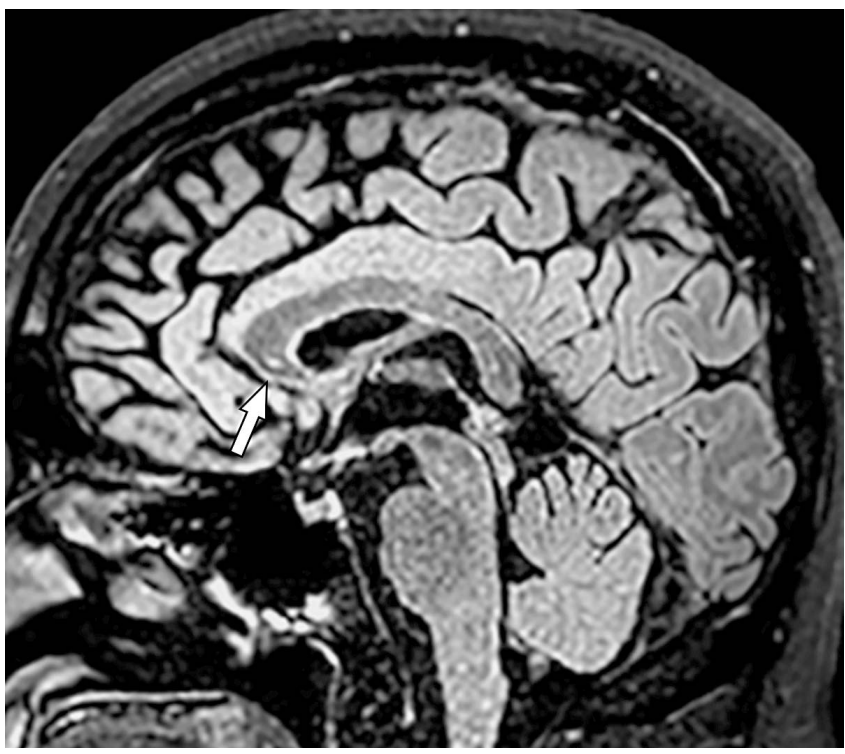

Figure 1. Sagittal FLAIR image discloses a small hyperintense lesion in the genu of the corpus callosum (arrow).

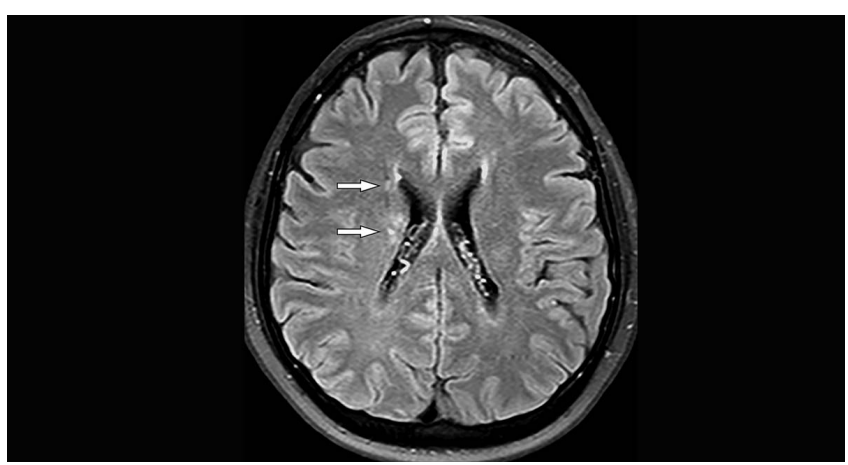

Figure 2. Axial FLAIR image shows some tiny scattered hyperintense lesions, more evident in the right cerebral periventricular white matter (arrows).

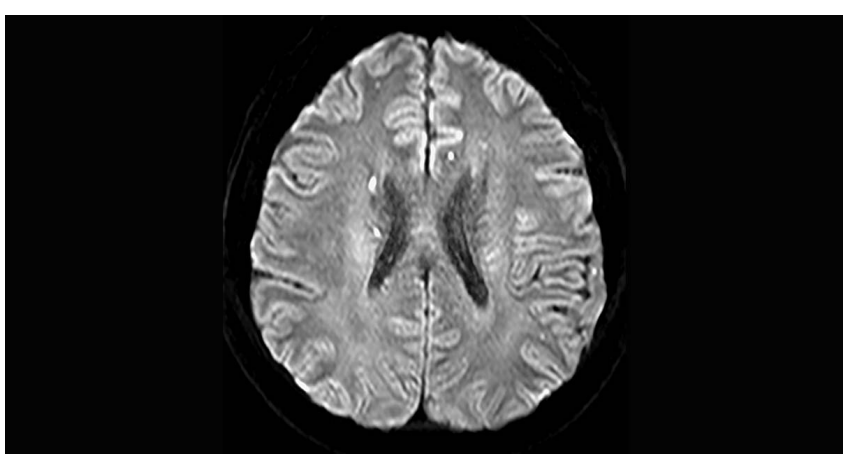

Figure 3. Axial diffusion-weighted image demonstrates restricted diffusion in some of the lesions, characterized by hyperintensity in this sequence.

\footnotetext{
'Departamento de Neurogenética, Faculdade de Medicina, Universidade de São Paulo, Sao Paulo SP, Brazil; ${ }^{2}$ Departamento de Neuroradiologia, Faculdade de Medicina, Universidade de São Paulo, Sao Paulo SP, Brazil;

${ }^{3}$ Setor de Córnea e Doenças Externas, Departamento de Oftalmologia, Faculdade de Medicina, Universidade de São Paulo, São Paulo SP, Brazil; ${ }^{4}$ Departamento de Neurologia, Faculdade de Medicina, Universidade de São Paulo, Sao Paulo SP, Brazil;

${ }^{5}$ Departamento de Neurologia, Hospital Samaritano, Sao Paulo SP, Brazil.

Correspondence: Fernando Freua; Rua Mato Grosso, 306 Cj 1601; 01239-040 São Paulo SP, Brasil; E-mail: fernando.freua@gmail.com Conflict of interest: There is no conflict of interest to declare.

Received 27 May 2014; Received in final form 12 June 2014; Accepted 02 July 2014.
} 


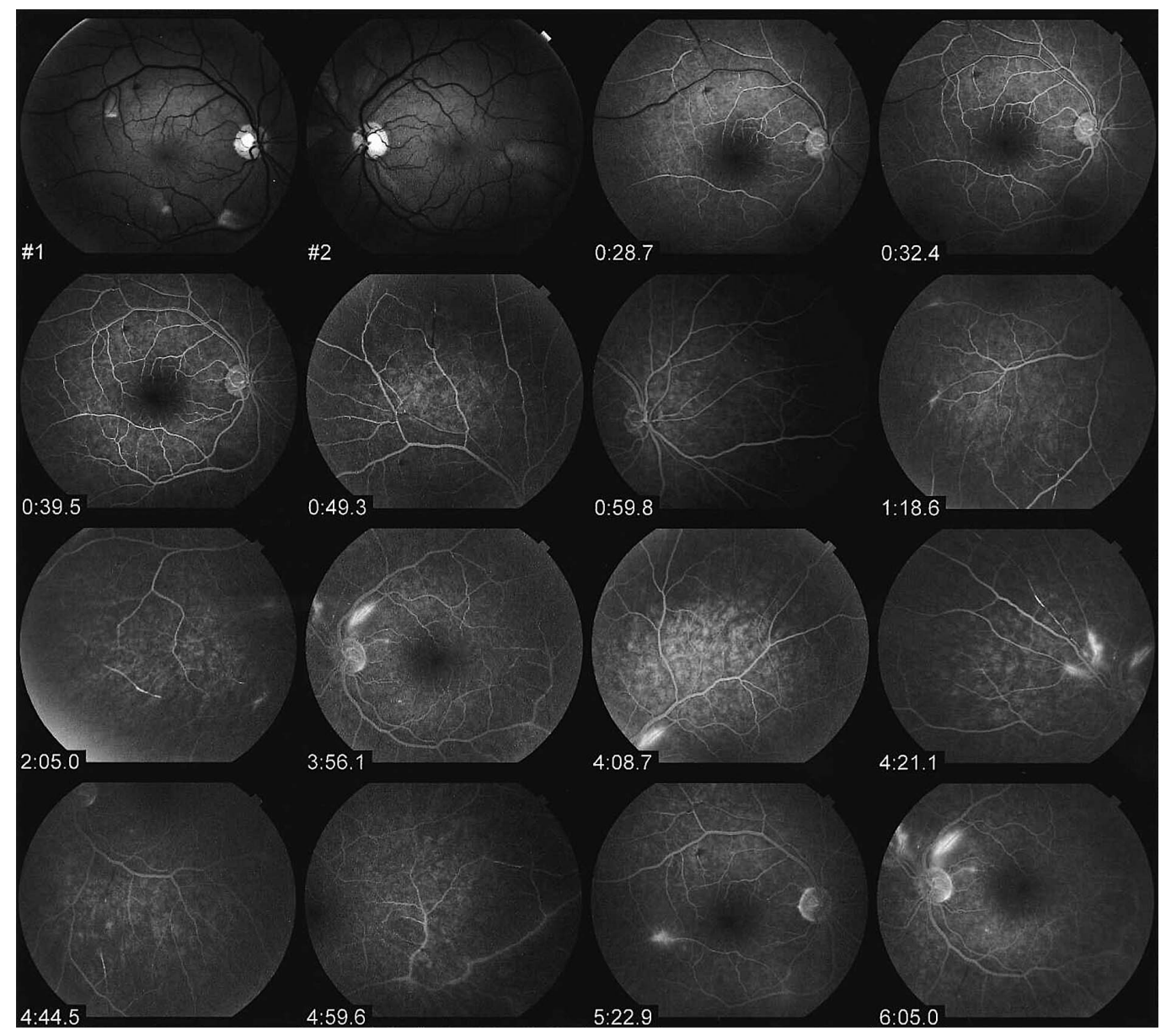

Figure 4. Fluorescein angiograms showing hemorrhages, staining of the vessel walls and leakage.

\section{References}

1. Susac JO, Hardman JM, Selhorst JB. Microangipathy of the brain and retina. Neurology. 1979;29(3):13-6. http://dx.doi.org/10.1212/wnl.29.3.313

2. Saw VP, Canty PA, Green CM, Briggs RJ, Cremer PD, Harrisber B et al. Susac syndrome: microangiopathy of the retina, cochlea and brain.
Clin Exp Ophtalmol. 2000;28(5):373-81. http://dx.doi.org/10.1046/ j.1442-9071.2000.00345.x

3. Do TH, Fisch C, Evoy F. Susac syndrome: report of four cases and review of the literature. AJNR Am J Neuroadiol. 2004;25(3):382-8. 